\title{
The development of anxiety disorders in childhood: an integrative review
}

\section{Article}

Published Version

Murray, L., Creswell, C. and Cooper, P. J. (2009) The development of anxiety disorders in childhood: an integrative review. Psychological Medicine, 39 (9). pp. 1413-1423. ISSN 1469-8978 doi: https://doi.org/10.1017/s0033291709005157 Available at https://centaur.reading.ac.uk/13912/

It is advisable to refer to the publisher's version if you intend to cite from the work. See Guidance on citing.

To link to this article DOI: http://dx.doi.org/10.1017/s0033291709005157

Publisher: Cambridge University Press

All outputs in CentAUR are protected by Intellectual Property Rights law, including copyright law. Copyright and IPR is retained by the creators or other copyright holders. Terms and conditions for use of this material are defined in the End User Agreement.

\section{www.reading.ac.uk/centaur}

\section{CentAUR}

Central Archive at the University of Reading

Reading's research outputs online 


\title{
The development of anxiety disorders in childhood: an integrative review
}

\author{
L. Murray*, C. Creswell and P. J. Cooper \\ Winnicott Research Unit, School of Psychology, University of Reading, Reading, UK
}

\begin{abstract}
We present an integrative review of the development of child anxiety, drawing on a number of strands of research. Family aggregation and genetic studies indicate raised vulnerability to anxiety in offspring of adults with the disorder (e.g. the temperamental style of behavioural inhibition, or information processing biases). Environmental factors are also important; these include adverse life events and exposure to negative information or modelling. Parents are likely to be key, although not unique, sources of such influences, particularly if they are anxious themselves. Some parenting behaviours associated with child anxiety, such as overprotection, may be elicited by child characteristics, especially in the context of parental anxiety, and these may serve to maintain child disorder. Emerging evidence emphasizes the importance of taking the nature of child and parental anxiety into account, of constructing assessments and interventions that are both disorder specific, and of considering bidirectional influences.
\end{abstract}

Received 28 February 2008; Revised 18 November 2008; Accepted 28 November 2008; First published online 12 February 2009

Key words: Anxiety, behavioural inhibition, child, development, parenting.

\section{Introduction}

Anxiety disorders in childhood and adolescence are common and disabling (Costello et al. 2004). They often run a chronic course and are associated with the development of other disorders, such as depression, conduct disorder or attention deficit disorder (Bittner et al. 2007). There have been several strands of research into the development of child anxiety. First, research has concerned vulnerability factors, especially biological characteristics (genetic, temperamental), and information processing styles. Second, research has concerned environmental influences that may increase risk for disorder, either alone or in combination with some vulnerability factor. These include adverse life events and learning routes, such as modelling and information transfer. This review considers these vulnerability and environmental factors, paying particular attention to the role of parents, who are likely to be key sources of at least some of these influences. Notably, recent research shows the importance for understanding the development and maintenance of child anxiety of integrating evidence concerning child vulnerability with that on parenting, and highlights the potential bidirectionality of child and parental influences. The review concludes with a schematic

* Address for correspondence: Professor L. Murray, Winnicott Research Unit, School of Psychology, University of Reading, Reading RG6 6AL, UK.

(Email: lynne.murray@reading.ac.uk) representation of this integration and a brief discussion of directions for future research and treatment.

\section{Vulnerability factors \\ Family aggregation and genetics}

The familiality of anxiety disorders found in adults (Hettema et al. 2001) has also been found in intergenerational studies of family aggregation. Thus, children whose parents have anxiety disorders exhibit an increase of anxiety disorders over the base rate themselves (Weissman et al. 1984; Turner et al. 1987; Biederman et al. 1991; Warner et al. 1995; Mancini et al. 1996). Similarly, parents of children with anxiety disorders have a raised rate of anxiety disorders compared to control parents (Last et al. 1987, 1991; Cooper et al. 2006), with the elevation of risk largely confined to mothers (Cooper et al. 2006).

The extent to which aggregation is accounted for by genetic transmission is uncertain because research has seldom involved samples of children with actual anxiety disorder, but instead has reported genetic effects on anxiety symptoms or certain endophenotypes, such as behavioural inhibition (discussed later). These studies consistently reveal a genetic influence of moderate magnitude (Gregory \& Eley, 2007), but one that varies depending on the child's sex (e.g. Eaves et al. 1997; Feigon et al. 2001) and, possibly, on age (e.g. Feigon et al. 2001). The magnitude of effects is also influenced by the information source: genetic influences 
are more significant, and shared environment less so, where the child anxiety is parent rated, and the reverse is the case where self-rated (Thapar \& McGuffin, 1995; Eaves et al. 1997). The extent to which studies have implicated shared and non-shared environmental factors has also varied as a function of the form of anxiety, although findings are inconsistent (Silove et al. 1995; Eaves et al. 1997; Legrand et al. 1999; Feigon et al. 2001; Eley et al. 2003; Ehringer et al. 2006).

Most of the search for a genetic substrate to child anxiety has centred around a functional polymorphism in the promoter region of the serotonin [5hydroxytryptamine (5-HT)] transporter (5-HTT) gene. A meta-analysis of studies involving adults found that the short allele was associated with a predisposition to anxiety and negative emotionality (Munafo et al. 2003); and it has also been found to be associated with increased amygdala activation to presentation of fearful faces (Hariri et al. 2002). Studies involving children have produced a more mixed picture. Thus, in one study no relationship was found between the 5-HTT gene and the fearful temperamental style of behavioural inhibition (Schmidt et al. 2002); and whereas shyness was found to be associated with the long form of the 5-HTT gene in one study (Arbelle et al. 2003), in another it was associated with the homozygous shortshort 5-HTT allele (Battaglia et al. 2005). This confused picture may partly be a function of looking for simple associations, when gene-pathology relationships are in fact moderated by other factors. Thus, some evidence suggests that 5-HTT status interacts with environmental factors to confer risk for the development of depression (Caspi et al. 2003; Kaufman et al. 2004). The same seems to be true for social anxiety: Fox et al. (2005) found that, controlling for temperamental status at age 4 years, the presence of the short 5-HTT allele significantly raised the risk of both objectively assessed behavioural inhibition and maternal reports of child shyness in 7-year-olds, but only where there had been reduced levels of social support. The significance of interactions of this sort is taken up below.

Familiality is therefore strong in child anxiety disorder, although the evidence for significant heritability is meagre, and the genetic substrate is poorly understood.

\section{Behavioural inhibition (BI)}

The term 'behavioural inhibition' (BI) has been used by Kagan (1989) and others to refer to a child temperamental pattern of responding characterized by fearfulness, reticence or restraint when faced with unfamiliar people or situations. In longitudinal research, around $50 \%$ children have been found to maintain their early BI classification through childhood (Kagan et al. 1988; Kagan, 1994; Turner et al. 1996) and adolescence (Kagan et al. 2007), with those classified as inhibited in infancy tending to show greater continuity than those who were uninhibited. Strong associations have been found between BI in children and anxiety disorders in parents (e.g. Rosenbaum et al. 1991; Rickman \& Davidson, 1994), and between anxiety disorders in parents and BI in children (e.g. Rosenbaum et al. 1988, 2000; Biederman et al. 2001a). Furthermore, in longitudinal research, early BI has been found to predict later frank anxiety disorder (Turner et al. 1996), especially of the social form (Hayward et al. 1998; Schwartz et al. 1999 ; Biederman et al. 2001a). However, despite this clear association between BI and anxiety disorder, it remains the case that only a proportion of those who are inhibited do go on to develop an anxiety disorder, and it is important to consider what factors might account for continuities and discontinuities (see below).

\section{Information processing}

It has been suggested that vulnerability to the development of anxiety may be reflected in biased information processing, in both attentional bias in relation to threat and biases in interpretation of ambiguous material (Rapee, 2001; Hudson \& Rapee, 2004; Rapee \& Spence, 2004). Attentional biases have certainly been identified in older anxious children (see review by Hadwin et al. 2006), although in younger children the evidence is less consistent (Martin \& Jones, 1995; Kindt et al. 1997). However, these studies have been cross-sectional, with already anxious subjects, and therefore cannot elucidate whether these biases represent vulnerability. One recent prospective study of infants of socially anxious mothers did find evidence for sensitivity to fearful faces, consistent with the possibility of a fundamental cognitive vulnerability (Creswell et al. 2008c); however, further prospective enquiry is required to establish the reliability of this finding and its longer-term clinical significance.

The evidence for interpretation biases in child anxiety is strong and consistent (Hadwin et al. 2006); in the main, however, the studies have also been crosssectional, and thus their role as vulnerability factors is not clear. Two prospective studies do provide some indication that interpretation bias may predate anxiety: Warren et al. (2000) found preschool-age children's negative story endings predicted anxiety 1 year later, controlling for earlier anxiety. Similarly, Creswell (2004) found children's negative interpretations of ambiguous stimuli predicted increased anxiety symptoms following transition to secondary school.

Although the evidence for information processing biases predating the onset of anxiety is scarce, 
identifying children vulnerable because of particular cognitions is a promising line of enquiry that could open up possibilities for preventive intervention.

\section{Environmental influences}

\section{Life events and difficulties}

Investigations of the role of adverse life events in the aetiology of childhood anxiety disorders have been influenced by the associative account, which suggests that fears and phobias are classically conditioned anxiety responses; that is, they develop from the paired association of a neutral stimulus with a traumatic event. Studies of the role of distinct, traumatic events have generally lacked control groups and been retrospective and therefore subject to 'plaintive bias' (Kendler et al. 2000); and although many people with a phobia do attribute onset to specific events (e.g. Ollendick \& King, 1991; Muris et al. 2002), many do not (e.g. Menzies \& Clarke, 1995). Similarly, many individuals experience a trauma but do not develop an anxiety disorder (e.g. Rachman, 1990). To account for such variability, contemporary learning accounts incorporate the role of pre-existing individual vulnerabilities, previous learning experiences and stressors, in addition to post-stressor experience (e.g. Ollendick, 1979; Beck, 1986; Barlow, 1988; Rapee, 2001; Muris et al. 2002).

With regard to more general life events, some prospective studies provide evidence consistent with their causal role. The study of Goodyer et al. (1988) found that, compared to non-anxious children, those with anxiety experienced more negative events in the 12month period preceding onset of disorder. Similarly, Phillips et al. (2005) found difficulties experienced in the first 5 years (e.g. a mother's change of partner) to predict anxiety disorder in adolescence, even controlling for current adversity. Nevertheless, studies also show reciprocal influences: thus, Swearingen \& Cohen (1985) found that child distress (anxiety or depression) predicted occurrence of subsequent adverse events, including those objectively rated as 'uncontrollable'. Research over a longer time-scale by Kim et al. (2003) similarly showed that, although life events increased the risk of internalizing problems, the latter then predicted further negative experiences.

Some studies suggest it is important to consider the type of event experienced. Eley \& Stevenson (2000) found, consistent with adult data (Finlay-Jones \& Brown, 1981), that trait anxiety in school-aged children was specifically associated with threat events; and Shanahan et al. (2008) found that living in a dangerous neighbourhood and parental drug use were specific risks for child anxiety disorder.
The processes whereby the experience of negative life events increases risk for disorder are likely to be multi-faceted. Early exposure to adversity may affect the child's developing physiological systems [e.g. the hypothalamic-pituitary-adrenal (HPA) axis (Phillips et al. 2005)] and the development of child cognitions, particularly concerning threat and control (Chorpita \& Barlow, 1998); and its effects may be mediated by parental perceptions of child vulnerability and consequent alterations in parenting practice (Creswell et al. 2008c). Finally, the association may be accounted for by some third variable (e.g. parental psychopatho$\log$ ).

\section{Modelling and information transfer}

In addition to the role of traumatic events, learning accounts have emphasized two further routes for the development of anxiety. The first concerns the child's observation of others' anxiety, and is generally referred to as a modelling or a vicarious acquisition process. The second concerns communication to the child of information regarding the threatening properties of the environment, usually termed informational acquisition (for reviews see Bandura, 1986; Rachman, 1990; King et al. 1998; Muris et al. 2002 ; Field, 2006; Mineka \& Zinbarg, 2006; Fisak \& Grills-Taquechel, 2007). In the course of naturally occurring social interactions, these two processes are likely to overlap, but for clarity we distinguish them here.

\section{Modelling}

In the modelling account of the development of anxiety, animal experiments, most notably those of Mineka and colleagues with rhesus monkeys, clearly show how persistent fears may develop following observation of others' fearful responses (Cook \& Mineka, 1987), with the extent of fearfulness varying as a function of the degree of fear modelled (Mineka, 1985). Notably, these studies show the effect to be restricted to stimuli for which a fearful response is evolutionarily advantageous, where there is a 'preparedness' for fear (e.g. for snakes but not flowers; Mineka, 1988). Individual differences in susceptibility are also found, with modelling effects attenuated by previous experience of mastery or control (Mineka et al. 1986).

Evidence from human studies confirms the importance of these processes. Clinical accounts of World War II experiences document, for example, how the display of fear by mothers during air raids determined whether children expressed similar fears (Lewis, 1942). Retrospective studies by adults with a range of phobias document modelling by others as having been a significant influence, particularly for animal phobias, 
blood phobia, social phobia and panic (see reviews by Mineka \& Zinbarg, 2006; Fisak \& Grills-Taquechel, 2007). Mothers' own reports of their manifest expression of fearfulness have also been found to be associated with child specific fears (Muris et al. 1996) and post-traumatic stress disorder (PTSD) symptoms (McFarlane, 1987).

More recently, researchers have directly observed the effect of parental modelling on child fearful responses. Thus, Gerull \& Rapee (2002) showed, in a non-anxious sample, how maternal modelled fear and disgust to potentially fear-provoking objects led to the expression of fearful and avoidant responses in 15- to 20-mont-olds. Similarly, de Rosnay et al. (2006) showed that maternal modelling of anxious versus non-anxious social responses to a stranger determined infants' subsequent expression of fear to the same unfamiliar adults. This process was recently examined longitudinally in an anxious population. Mothers with social phobia, and non-anxious control group mothers, conversed with a stranger while their infant watched, and the infant's response to the stranger was rated. Maternal expressed anxiety at 10 months, which was, as expected, more prominent in the social phobia group, predicted increased infant avoidance of the stranger at 14 months (Murray et al. 2008).

In sum, there is strong laboratory evidence that modelling plays an important causal role in the intergenerational transmission of anxiety, although the manner in which this process operates naturalistically remains to be elucidated.

\section{Information acquisition}

The role of providing information conveying threat in the development of child fears and avoidance has been examined in a series of experimental studies with normal populations of 6- to 13-year-old children by Field and colleagues (Field \& Lawson, 2003; Field et al. 2003; Lawson et al. 2007). Information that was either positive, negative or neutral was presented to children concerning novel non-social stimuli (e.g. fictitious animals) and various social situations. There were consistent findings of the impact of negative information on child fear and avoidance, and also evidence for the persistence of effects over several months. Moreover, the nature of information delivery, its source, and also previous experience all influenced the impact, suggesting that relatively complex processes are involved.

Learning accounts of the development of child fears and anxiety have consistently identified parents as playing a particularly important role through instruction and information transfer (Hadwin et al. 2006). Indeed, a large body of research with normal populations has shown how, through tuition and spontaneous conversations, parents both consciously and unconsciously transmit evaluative cognitions to their child (Fivush, 1991; Nelson, 1993; Denham et al. 1994), with systematic associations being found between the nature of parental discourse and children's own cognitive and socio-emotional functioning (Dunn et al. 1991; Fivush \& Vasudeva, 2002). Observational studies of anxious populations provide some evidence for these processes in the transmission of disorder, with distinctive features of parent-child conversations being identified. Thus, in one study by Whaley et al. (1999) and Moore et al. (2004), anxious parents were found to make more catastrophizing comments to their children than non-anxious parents. Suveg et al. (2005) found that parents of anxious children were less likely to refer to positive emotions than were parents of non-anxious children. Barrett and colleagues found that, following parent-child discussion, anxious children became more likely to choose avoidant solutions to hypothetical threats (Barrett et al. 1996; Dadds \& Barrett, 1996).

Experimental studies indicate that information transfer is relevant to the transmission of anxiety, and observational evidence is consistent with this process in intergenerational transmission.

\section{Other parental influences: warmth and control}

In addition to parents' modelling of anxious responses, and their provision of information to the child that may directly induce fear and anxiety, a principal focus for research on the role of parent-child relationships in the development of child anxiety has been parental lack of warmth or rejection, and parental overcontrol. Lack of parental warmth has been considered important because it may lead to the child's believing that the environment is fundamentally hostile and threatening, and to a sense of low self-worth and competence (Parker, 1983; Bogels \& Tarrier, 2004). With regard to parental overcontrol, a parent's excessive regulation of the child's activities and routines, and their discouragement of independence, is likely to promote a limited sense of competence and mastery, and may serve to reinforce child avoidance of challenge (Parker, 1983; Chorpita \& Barlow, 1998). Three reviews of parenting (Wood et al. 2003; DiBartolo \& Helt, 2007; McLeod et al. 2007) conclude that the evidence for parental lack of warmth being associated with child anxiety is inconsistent, whereas that for parental overcontrol is stronger. One of these reviews (McLeod et al. 2007), a quantitative meta-analysis, is notable in having examined the role of methodological factors (e.g. informant, assessment method), whether child anxiety diagnoses or else anxious /fearful symptoms were assessed, and subdimensions of the two 
parenting constructs. This review showed that effects were strongest where direct observations were made of parenting in contrast to questionnaire or interview assessment, and for diagnosed child anxiety rather than symptoms. With regard to parenting dimensions, overall effect sizes for rejection and control, across all types of study, were only 0.20 (i.e. accounting for $4 \%$ variance in child outcome) and 0.25 (6\% variance) respectively. However, subdimensions were important to consider; thus, although the effect size for warmth was just 0.06, effect sizes for overinvolvement, aversiveness and withdrawal were $0.22-0.23$, and that for autonomy granting was 0.42 .

Although research interest in parenting outlined above has largely focused on closely observed parentchild interactions and the assessment of proximal parenting processes, it is important to note that wider parenting practices are also likely to be implicated in the development of child anxiety. Thus, parents' decisions concerning, for example, the use of day-care, and family socialization and recreational activities, all stand to enhance or else limit child exposure to potential challenges beyond the home, and thereby the opportunity to develop coping skills (see reviews by Chorpita \& Barlow, 1998; Bogels \& BrechmanToussaint, 2006).

In sum, a range of parenting practices have been considered as relevant to child anxiety; of these, lack of autonomy granting seems to be particularly important at the micro-level of observed parent-child interactions and also wider, more general parenting practices.

\section{Further issues in parenting}

Two further issues regarding parenting effects are important to consider, namely the direction of effects and the specificity of effects.

\section{Direction of effects}

Although certain parenting practices have been found to be more common in the context of anxiety, the question arises of whether these are (i) a function of the parents who, as the family aggregation studies show, are themselves frequently anxious, or (ii) generated as a response to having an anxious child, or else (iii) result from some interaction between parent and child characteristics. This question can be addressed only in studies that include assessment of both parent and child. Such a design has seldom been used. Moore et al. (2004) observed parent-child interactions in four groups: anxious and non-anxious mothers with either anxious or non-anxious children. They found both maternal warmth and autonomy granting to show a main effect of child diagnosis, with no effect of the mother's anxiety status. For 'catastrophizing', although there was a main effect of maternal diagnosis, within the group of non-anxious mothers those with anxious children were significantly more likely to show this behaviour than those of children who did not have anxiety disorder. This suggests that child influences on parenting are as important to consider as parental characteristics.

Studies using experimental manipulations, longitudinal designs, cross-over between parents and children, or those including sibling comparisons, are also potentially informative regarding the question of the contributions of parent and child characteristics to parenting quality. The influence on parenting of the parents' prior experience of their child is apparent from the study of Dumas \& LaFreniere (1993), who found that mothers of anxious children interacted more negatively than mothers of other groups of children (e.g. competent or aggressive) when with their own child, but more positively when with another anxious child, suggesting that their capacity to behave positively was intact but was compromised by the history of the relationship with their child. The studies of anxious children by Hudson \& Rapee (2002) and Barrett et al. (2005), which used sibling controls, found that mothers behaved similarly towards their two children, and were more overinvolved/controlling with both of them than were comparison mothers with their non-anxious children. However, although these findings were interpreted as showing parenting to be more a function of maternal rather than child characteristics, it should be noted that the anxious children's siblings often had anxiety symptoms themselves (Hudson \& Rapee, 2002), and did not differ in their behaviour from the anxious child (Barrett et al. 2005), leaving open the possibility of child effects being important. Thus, although sibling studies are useful in disentangling the relative contributions of different individuals, it is important that full account is taken of participant characteristics.

Several studies, typically with young children or infants, have taken child temperament or BI into account when examining parenting. It seems that, among anxious, but not non-anxious, parents, infant or child inhibition may provoke parenting styles that contribute further to child anxiety. For example, Hirshfeld et al. (1997) found that maternal criticism of the child was a function of an interaction between child inhibition and maternal anxiety status; that is, anxious mothers of inhibited children were likely to be critical (65\% were so), whereas those with non-inhibited children were not $(18 \%)$. Among nonanxious mothers, by contrast, child inhibition was unrelated to maternal criticism. The study of Murray et al. (2008) produced similar findings: mothers with 
social phobia showed low levels of encouragement to their infants to engage with a stranger only if their infant was behaviourally inhibited, whereas among non-anxious mothers, the opposite was true. This suggests that, whereas non-anxious mothers respond to their inhibited child by facilitating the child's positive engagement with potential challenges, anxious parents respond to child inhibition by encouraging their child to avoid potential threat.

In fact, longitudinal evidence suggests that infant or child BI is likely to be a predictor of subsequent child anxiety only when accompanied by problematic parenting styles. Thus, in the study of Murray et al. (2008), the development of avoidance of strangers by inhibited infants of mothers with social phobia was accounted for by their mothers' failure to encourage infant social responsiveness. Similarly, Rubin et al. (2002) found that children who were inhibited at age 2 years only became socially reticent by 4 years if their mothers had initially been controlling (intrusive or overprotective) or derisive towards their child. Warren \& Simmens (2005) also found, in a large epidemiological sample, that infants rated as having a difficult temperament at 6 months were only likely to develop symptoms of anxiety and depression at 2 years if their mother was insensitive. Aside from such proximal parenting influences, wider socialization experiences also seem to influence the trajectory of early inhibition. Both Furman et al. (1979) and Fox et al. (2001) found that the development of infants who showed early vulnerability for inhibited or withdrawn behaviour was positive if the child experienced opportunities for socializing with others (e.g. through day-care).

Thus, although neither BI nor parenting factors have emerged as strongly associated with child anxiety when considered singly, their co-occurrence does seem to be of considerable aetiogical significance; in particular, parents who are themselves already anxious are likely to respond to child vulnerability with parenting practices that may further reinforce the child's difficulties.

\section{Specificity of parenting effects}

Two questions arise regarding specificity of effects: first, whether particular parenting characteristics are uniquely associated with child anxiety disorders, rather than with more general child psychopathology; and second, whether some parenting characteristics are specifically related to subtypes of both parent and child anxiety disorder. In general, research on risks for childhood anxiety has not addressed these issues, and studies comparing the parenting of anxious children with that of children with other disorders have produced inconsistent findings. For example, compared to mothers of aggressive children, those of anxious children have been found to be both more negative (Dumas \& LaFreniere, 1993; Dumas et al. 1995), less negative (Stubbe et al. 1993), and indistinguishable in terms of negativity (Hudson \& Rapee, 2001).

Given the extent of co-morbidity between childhood disorders, it is particularly important to take different child symptom profiles into account when addressing the issue of specificity. Both the Virginia Twin Study (Kendler et al. 2000) and the Great Smoky Mountain epidemiological study (Shanahan et al. 2008) are notable for having used multiple informants, and for having carefully controlled for co-morbid disorders. The former showed cold, overprotective and authoritarian parenting all to contribute to offspring anxiety, over and above their impact on other child diagnoses, whereas the latter suggested overintrusive parenting may be specifically associated with anxiety disorders rather than conduct disorder, oppositional defiant disorder (ODD) and depression.

Little evidence exists concerning specificity in the effects of parenting within the anxiety disorders. Indeed, a notable feature of research into parenting effects is that different anxiety disorders in both child and parent populations have generally been grouped together. Furthermore, the conditions for assessing parent-child relationships have often been nonspecific, obscuring parental and child difficulties that might be elucidated only in contexts that are disorder relevant. Two recent studies have sought to address these issues. Murray et al. (2007) found that, compared to non-anxious control mothers, those with social phobia, but not those with generalized anxiety disorder (GAD), showed parenting difficulties in the context of a mild social challenge (i.e. interacting with an unfamiliar person) and their infants were similarly specifically affected. Wood et al. (2006) compared parenting in groups where children had either separation anxiety disorder (SAD) or other anxiety disorders (social phobia or GAD), in a task designed specifically to elucidate parental overprotection because child dependency on the parents promoted by this behaviour was hypothesized to be a specific risk for SAD. In line with predictions, overprotection was significantly correlated with SAD but not with other disorders.

Both the Smoky Mountain and the Virginia twin studies also examined the question of specificities in parenting within the anxiety disorders. Harsh discipline was associated with GAD in the Smoky Mountain study, as was the similar dimension of authoritative parenting in the Virginia study. However, in the latter overprotection was also important; in the Smoky Mountain study, no other parenting dimension 


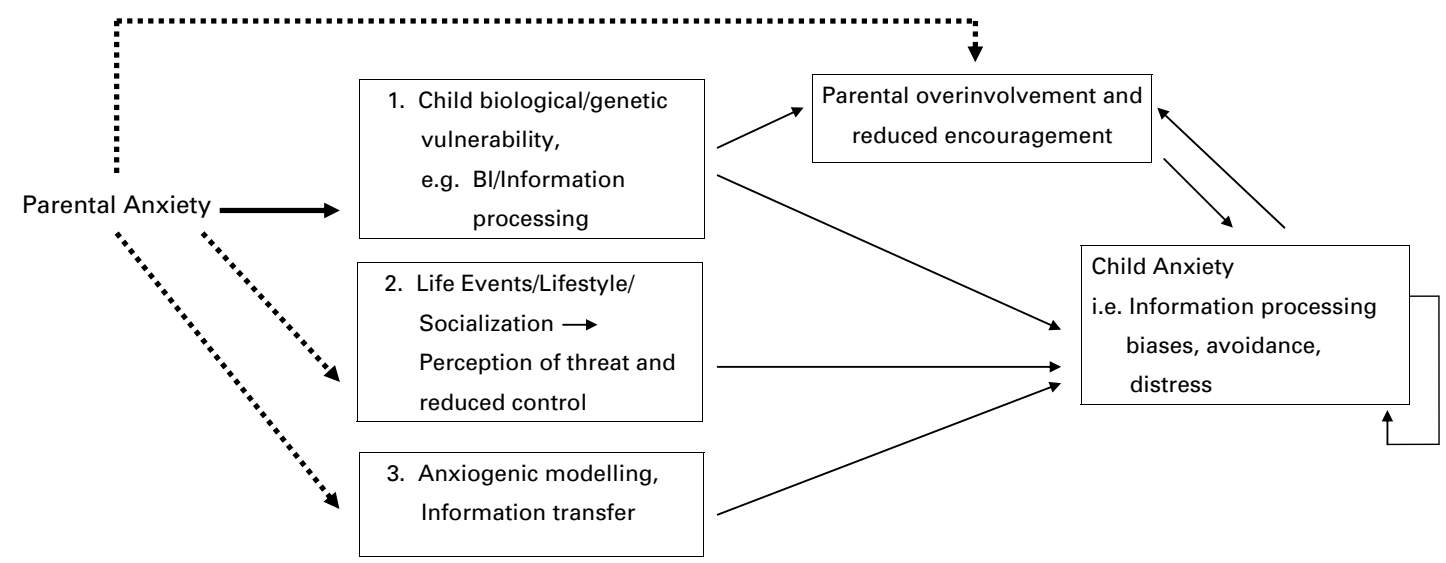

Fig. 1. Pathways to child anxiety. $\longrightarrow$, Parental anxiety accounts for the factor $; \cdots \rightarrow \rightarrow$, Parental anxiety raises the risk of the factor. BI, Behavioural inhibition.

contributed significantly to social phobia or child SAD, over and above their contribution to other child disorders, whereas in the Virginia study, all three parenting dimensions assessed made significant contributions to phobias (including social phobia), independently of effects on other disorders.

In sum, although few studies have addressed the issue of specificity, a body of evidence is beginning to emerge implicating particular styles of parenting in particular forms of child anxiety.

\section{Summary and directions for future research}

Taken together, the evidence reviewed here suggests an interplay between several factors in the development of child anxiety, as illustrated in Fig. 1.

First, family aggregation and genetic studies indicate raised vulnerability to anxiety in offspring of adults with the disorder. Such vulnerability may be manifest in terms of behavioural inhibition, and it is possible that particular information processing biases also represent genetically mediated vulnerability. Parental anxiety may also place offspring at increased risk for disorder through exposure to negative life events, which may directly increase the risk of child anxiety, or do so through diminishing the child's sense of control. In addition, anxious parents may, as a function of their own disorder, place limits on their children's wider experiences, thereby restricting their opportunities to encounter and tackle challenging circumstances. Research on parenting suggests that certain parenting styles associated with child anxiety occur directly as a function of parental anxiety disorder, most notably behaviourally expressed anxiety and anxious cognitions such as catastrophizing and overattribution of threat, and these may serve to promote child anxiety through learning processes of modelling and information transfer. Although the role of parental anxiety in conferring risk to the child has been emphasized, it is important to note that child anxiety can occur in the absence of parental disorder, and that risk factors (e.g. the occurrence of adverse events, provision of negative information) may impact on the child independently of parental behaviour. Furthermore, some parenting dimensions associated with child disorder seem to be provoked by particular child characteristics, such as BI or, indeed, child anxiety itself. These include behaviours such as overinvolvement or overprotection, lack of encouragement or autonomy promotion, and negative or aversive behaviour. Notably, such behaviours are especially likely to arise in parents who are themselves prone to anxiety. These parenting styles, initiated by the child's behaviour, also play a role in maintaining child inhibition and anxiety. This being so, treatment research manipulating different parenting dimensions stands to make a significant contribution to the understanding of mechanisms influencing the maintenance of child disorder, in addition to the improvement of child outcome. Finally, little research has so far directly addressed the question of the specificity of parenting styles relevant to different child anxiety disorders; nevertheless, emerging evidence of specificity of effects suggests that it will be important in future studies to control adequately for the nature of both child and parent anxiety, and to design observational frames, coding schemes and interventions that are relevant to the disorder in question.

The proposed model has potential implications for the prevention and clinical management of child anxiety disorders. Although individual vulnerability factors (e.g. BI) may not be strong predictors of later anxiety disorder, identifying children who experience a combination of vulnerability factors (e.g. high BI and 'anxiogenic' parenting) may allow effective targeting of preventive interventions. Furthermore, the model 
identifies key parenting practices that are likely to require specific intervention (e.g. reduced encouragement). The presence of high parental anxiety is likely to be a barrier to optimal child treatment outcome (e.g. Cobham et al. 1998; Creswell et al. 2008c); however, whether it is necessary to address parental anxiety itself or whether it is sufficient to deal only with the parenting consequences of that anxiety requires further empirical investigation.

\section{Declaration of Interest}

None.

\section{References}

Arbelle S, Benjamin J, Golin J, Kremer I, Belmaker RH, Ebstein RP (2003). Relation of shyness in grade school children to the genotype for the long form of the serotonin transporter promoter region polymorphisms. American Journal of Psychiatry 160, 671-676.

Bandura A (1986). Social Foundations of Thought and Action: A Social Cognitive Theory. Prentice-Hall: Englewood Cliffs, NJ.

Barlow DH (1988). Anxiety and its Disorders: The Nature and Treatment of Anxiety and Panic. Guilford Press: New York.

Barrett PM, Fox T, Farrell L (2005). Parent-child interactions with anxious children and their siblings: an observational study. Behavior Change 22, 220-235.

Barrett PM, Rapee RM, Dadds MR (1996). Family treatment of childhood anxiety: a controlled trial. Journal of Consulting and Clinical Psychology 64, 333-342.

Battaglia M, Ogliari A, Zanoni A, Citterio A, Pozzoli U, Giorda R, Maffei C, Marino C (2005). Influence of the serotonin supporter gene and shyness on cerebral responses to facial expressions. Archives of General Psychiatry 62, 85-94.

Beck AT (1986). Cognitive approaches to anxiety disorders. In Anxiety Disorders: Psychological and Biological Perspectives (ed. B. F. Shaw, Z. V. Segal, T. M. Vallis and F. E. Cashman), pp. 115-136. Plenum Press: New York.

Biederman J, Faraone S, Hirshfeld-Becker DR, Friedman D, Robin JA, Rosenbaum JF (2001a). Patterns of psychopathology and dysfunction in high-risk children of parents with panic disorder and major depression. American Journal of Psychiatry 158, 49-57.

Biederman J, Hirshfeld-Becker DR, Rosenbaum JF, Hérot C, Friedman D, Snidman N, Kagan J, Faraone SV (2001b). Further evidence of an association between behavioral inhibition and social anxiety in children. American Journal of Psychiatry 158, 1673-1679.

Biederman J, Rosenbaum JF, Bolduc EA, Faraone SV, Hirshfeld DR (1991). A high risk study of young children of parents with panic disorder and agoraphobia with and without comorbid major depression. Psychiatry Research 37, 333-348.

Bittner A, Egger HL, Erklanli A, Costello J, Foley DL, Angold A (2007). What do childhood anxiety disorders predict? Journal of Child Psychology and Psychiatry 48, 1174-1183.

Bogels SM, Brechman-Toussaint ML (2006). Family issues in child anxiety: attachment, family functioning, parental rearing and beliefs. Clinical Psychology Review 26, 834-856.

Bogels SM, Tarrier N (2004). Unexplored issues and future directions in social phobia research. Clinical Psychology Review 24, 731-736.

Caspi A, Snudgen K, Moffitt TE, Taylor A, Craig IW, Harrington H, McLay J, Mill J, Martin J, Braithewaite A, Poulton R (2003). Influence of life stress on depression: moderation by a polymorphism in the 5 -HTT gene. Science 301, 386-389.

Chorpita BF, Barlow DH (1998). The development of anxiety: the role of control in the early environment. Psychological Bulletin 124, 3-21.

Cobham VE, Spence SH, Dadds MR (1998). The role of parental anxiety in the treatment of childhood anxiety. Journal of Consulting and Clinical Psychology 66, 893-905.

Cook M, Mineka S (1987). Second-order conditioning and overshadowing in the observational conditioning of fear in monkeys. Behavior Research and Therapy 25, 349-364.

Cooper PJ, Fearn V, Willetts L, Seabrook H, Parkinson M (2006). Affective disorder in the parents of a clinic sample of children with anxiety disorders. Journal of Affective Disorders 93, 205-212.

Costello J, Egger HL, Angold A (2004). Developmental epidemiology of anxiety disorders. In Phobic and Anxiety Disorders in Children and Adolescents (ed. T. H. Ollendick and J. S. March), pp. 61-91. Oxford University Press: New York.

Creswell C (2004). The Development of Anxious Cognitions in Children. Doctoral dissertation, University College London, UK.

Creswell C, O'Connor T, Brewin C (2008a). The impact of parents' expectations on parenting behavior: an experimental investigation. Behavioral and Cognitive Psychotherapy 36, 483-490.

Creswell C, Willetts L, Murray L, Singhal M, Cooper P (2008b). Treatment of child anxiety: an exploratory study of the role of maternal anxiety and behaviours in treatment outcome. Clinical Psychology and Psychotherapy 15, 38-44.

Creswell C, Woolgar M, Cooper P, Giannakakis A, Schofield E, Young A, Murray L (2008c). Processing of faces and emotional expressions in infants at risk of social phobia. Cognition and Emotion 22, 437-458.

Dadds MR, Barrett PM (1996). Family processes in child and adolescent anxiety and depression. Behavior Change 13, 231-239

Denham S, Zoller D, Couchard E (1994). Socialisation of pre-schoolers emotion understanding. Developmental Psychology 30, 928-936.

de Rosnay M, Cooper PJ, Tsigaras N, Murray L (2006). Transmission of social anxiety from mother to infant: an experimental study using a social referencing paradigm. Behavior Research and Therapy 44, 1165-1175.

DiBartolo PM, Helt M (2007). Theoretical models of affectionate versus affectionless control in anxious families: a critical examination based on observations of parent-child interactions. Clinical Child and Family Psychology 10, 253-274. 
Dumas JE, LaFreniere PJ (1993). Mother-child relationships as sources of support or stress: a comparison of competent, average, aggressive, and anxious dyads. Child Development 64, 1732-1754.

Dumas JE, Serketich WJ, LaFreniere PJ (1995). 'Balance of power' : a transactional analysis of control in mother-child dyads involving socially competent, aggressive, and anxious children. Journal of Abnormal Psychology 104, 104-113.

Dunn J, Brown J, Beardsall L (1991). Family talk about feeling states and children's later understanding of others' emotions. Developmental Psychology 27, 448-455.

Eaves LJ, Silberg JL, Meyer JM, Maes HH, Simonoff E, Pickles A, Rutter M, Neale MC, Reynolds CA, Erikson MT, Heath AC, Loeber R, Truett KR, Hewitt JK (1997). Genetics and developmental psychopathology: 2. The main effects of genes and environment on behavioral problems in the Virginia Twin Study of Adolescent Behavioral Development. Journal of Child Psychology and Psychiatry 38, 965-980.

Ehringer MA, Rhee SH, Young S, Corley R, Hewitt JK (2006). Genetic and environmental contributions to common psychopathologies of childhood and adolescence: a study of twins and their siblings. Journal of Abnormal Child Psychology 34, 1-17.

Eley TC, Bolton D, O'Connor TG, Perrin S, Smith P, Plomin R (2003). A twin study of anxiety-related behaviors in pre-school children. Journal of Child Psychology and Psychiatry 44, 945-960.

Eley TC, Stevenson J (2000). Specific life events and chronic experiences differentially associated with depression and anxiety in young twins. Journal of Abnormal Child Psychology 28, 383-394.

Feigon SA, Wladman ID, Levy F, Hay AD (2001). Genetic and environmental influences on separation anxiety disorder symptoms and their moderation by age and sex. Behavior Genetics 31, 403-411.

Field AH, Lawson J (2003). Fear information and the development of fears during childhood: effects on implicit fear responses and behavioral avoidance. Behavior Research and Therapy 41, 1277-1293.

Field AP (2006). Is conditioning a useful framework for understanding the development and treatment of phobias? Clinical Psychology Review 26, 857-875.

Field AP, Hamilton SJ, Knowles KA, Plews EL (2003). Fear information and social phobic beliefs in children: a prospective paradigm and preliminary results. Behavior Research and Therapy 41, 113-123.

Finlay-Jones R, Brown GW (1981). Types of stressful life events and the onset of anxiety and depressive disorders. Psychological Medicine 11, 803-815.

Fisak B, Grills-Taquechel AE (2007). Parental modeling, reinforcement, and information transfer: risk factors in the development of child anxiety? Clinical Child and Family Psychology 10, 213-231.

Fivush R (1991). The social construction of personal narratives. Merrill Palmer Quarterly 37, 59-82.

Fivush R, Vasudeva A (2002). Remembering to relate: socioemotional correlates of mother-child reminiscing. Journal of Cognition and Development 3, 73-90.
Fox NA, Henderson HA, Marshall PJ, Nichols KE, Ghera MM (2005). Behavioral inhibition: linking biology and behavior within a developmental framework. Annual Review of Psychology 56, 235-262.

Fox NA, Henderson HA, Rubin KH, Calkins SD, Schmidt LA (2001). Continuity and discontinuity of behavioral inhibition and exuberance: psychophysiological and behavioral influences across the first four years of life. Child Development 72, 1-21.

Furman W, Rahe DF, Hartup WW (1979). Rehabilitation of socially withdrawn preschool children through mixed-age and same-age socialization. Child Development 50, 915-922.

Gerull FC, Rapee RM (2002). Mother knows best: effects of maternal modelling on the acquisition of fear and avoidance behavior in toddlers. Behavior Research and Therapy 40, 279-287.

Goodyer IM, Wright C, Altham PME (1988). Maternal adversity and recent stressful life events in anxious and depressed children. Journal of Child Psychology and Psychiatry 29, 651-667.

Gregory AM, Eley TC (2007). Genetic influences on anxiety in children: what we've learned and where we're heading. Clinical Child and Family Psychology Review 10, 199-212.

Hadwin JA, Garner M, Perez-Olivas G (2006). The development of information processing biases in childhood anxiety: a review and exploration of its origins in parenting. Clinical Psychology Review 26, 876-894.

Hariri AR, Mattay VS, Tessitore A, Kolochana B, Fera F, Goldman D, Egan MF, Weinberger DR (2002). Serotonin transporter genetic variation and the response of the human amygdale. Science 297, 400-403.

Hayward C, Killen JD, Kraemer KC, Taylor CB (1998). Linking self-reported childhood behavioral inhibition to adolescent social phobia. Journal of the American Academy of Child and Adolescent Psychiatry 37, 1308-1316.

Hettema JM, Neale MC, Kendler KS (2001). A review and meta-analysis of the genetic epidemiology of anxiety disorders. American Journal of Psychiatry 158, 1568-1578.

Hirshfeld DR, Biederman J, Brody L, Faraone SV, Rosenbaum JF (1997). Expressed emotion toward children with behavioral inhibition: associations with maternal anxiety disorder. Journal of the American Academy of Child and Adolescent Psychiatry 36, 910-917.

Hudson JL, Rapee RM (2001). Parent-child interactions and anxiety disorders: an observational study. Behavior Research and Therapy 39, 1411-1427.

Hudson JL, Rapee RM (2002). Parent-child interactions in clinically anxious children and their siblings. Journal of Clinical Child and Adolescent Psychology 31, 548-555.

Hudson JL, Rapee RM (2004). From anxious temperament to disorder: an etiological model of generalized anxiety disorder. In Generalized Anxiety Disorder: Advances in Research and Practice (ed. R. G. Heimberg, C. L. Turk and D. S. Mennin), pp. 51-74. Guilford Press: New York.

Kagan J (1989). Temperamental contributions to social behavior. American Psychologist 44, 668-674.

Kagan J (1994). Inhibited and uninhibited temperaments. In Prevention and Early Intervention: Individual Differences as Risk Factors for the Mental Health of Children (ed. W. B. Carey and S. C. McDevitt), pp. 35-41. Brunner/Mazel: New York. 
Kagan J, Reznick JS, Snidman N, Gibbons J, Johnson MO (1988). Childhood derivatives of inhibition lack of inhibition to the unfamiliar. Child Development 59, 1580-1589.

Kagan J, Snidman N, Kahn V, Towsley S (2007). The Preservation of Two Infant Temperaments into Adolescence. Monographs of the Society for Research in Child Development, No. 287. Blackwell: Boston.

Kaufman J, Yang BZ, Douglas-Palumberi H, Houshyar S, Lipschitz D, Krystal JH, Gelernter J (2004).

Social supports and the serotonin transporter gene moderate depression in maltreated children. Proceedings of the National Academy of Sciences USA 101, 17316-17421.

Kendler KS, Myers J, Prescott CA (2000). Parenting and adult mood, anxiety and substance disorders in female twins: an epidemiological, multi-informant, retrospective study. Psychological Medicine 30, 281-294.

Kim KJ, Conger RD, Elder Jr. GH, Lorenz FO (2003). Reciprocal influences between stressful life events and adolescent internalizing and externalizing problems. Child Development 74, 127-143.

Kindt M, Bierman JS, Brosschot JS (1997). Cognitive bias in spider fear and control children: assessment of emotional interference by a card format and a single-trial format of the Stroop. Journal of Experimental Child Psychology 66, 163-179.

King NJ, Eleonora G, Ollendick TH (1998). Etiology of childhood phobias: current status of Rachman's three pathways theory. Behavior Research and Therapy 36, 297-309.

Last CG, Hersen M, Kazdin AE, Francis G, Grubb HJ (1987). Psychiatric illness in the mothers of anxious children. American Journal of Psychiatry 144, 1580-1583.

Last CG, Hersen M, Kazdin AE, Orvaschel H, Perrin S (1991). Anxiety disorders in children and their families. Archives of General Psychiatry 48, 928-939.

Lawson J, Banerjee R, Field AP (2007). The effects of verbal information on children's fear beliefs about social situations. Behavior Research and Therapy 45, 21-37.

Legrand LN, McGue M, Iacono WG (1999). A twin study of state and trait anxiety in childhood and adolescence. Journal of Child Psychology and Psychiatry 40, 953-958.

Lewis A (1942). Incidence of neurosis in England under war conditions. Lancet 2, 175-183.

Mancini C, van Ameringen M, Szatmari P, Fugere C, Boyle M (1996). A high risk pilot study of the children of adults with social phobia. Journal of the Academy of Child and Adolescent Psychiatry 35, 1511-1517.

Martin M, Jones GV (1995). Integral bias in the cognitive processing of emotionally linked pictures. British Journal of Psychology 86, 419-435.

McFarlane AC (1987). Posttraumatic phenomena in a longitudinal study of children following a natural disaster. Journal of the American Academy of Child and Adolescent Psychiatry 26, 764-769.

McLeod BD, Wood JJ, Weisz JR (2007). Examining the association between parenting and childhood anxiety: a meta-analysis. Clinical Psychology Review 27, 155-172.
Menzies RG, Clarke JC (1995). The etiology of phobias: a nonassociative account. Clinical Psychology Review 15, 23-48.

Mineka S (1988). A primate model of phobic fears. In Theoretical Foundations of Behavior Therapy (ed. H. Eysenck and I. Martin), pp. 81-111. Plenum Press: New York.

Mineka S, Davidson M, Cook M, Kein R (1984). Observational conditioning of snake fear in rhesus monkeys. Journal of Abnormal Psychology 93, 355-372.

Mineka S, Gunner M, Champoux M (1986). Control and early emotional development: infant rhesus monkeys reared in controllable versus uncontrollable environments. Child Development 57, 1241-1256.

Mineka S, Zinbarg R (2006). A contemporary learning theory perspective on the etiology of anxiety disorders: it's not what you thought it was. American Psychologist 61, 10-26.

Moore PS, Whaley SE, Sigman M (2004). Interactions between mothers and children: impacts of maternal and child anxiety. Journal of Abnormal Psychology 113, 471-476.

Munafo MR, Clark TG, Moore LR, Payne E, Wlaton R, Flint J (2003). Genetic polymorphisms and personality in healthy adults: a systematic review and meta-analysis. Molecular Psychiatry 8, 471-484.

Muris P, Merckelbach H, Jong PJ, Ollendick TH (2002). The etiology of specific fears and phobias in children: a critique of the non-associative account. Behavior Research and Therapy 40, 185-195.

Muris P, Steernmen P, Merckelbach H, Meesters C (1996). The role of parental fearfulness and modeling in children's fear. Behavior Research and Therapy 34, 265-268.

Murray L, Cooper PJ, Creswell C, Schofield E, Sack C (2007). The effects of maternal social phobia on mother-infant interactions and infant social responsiveness. Journal of Child Psychology and Psychiatry 48, 45-52.

Murray L, DeRosnay M, Pearson J, Bergeron C, Schofield L, Royal-Lawson M, Cooper PJ (2008). Intergenerational transmission of maternal social anxiety: the role of the social referencing process. Child Development 79, 1049-1064.

Nelson K (1993). The psychological and social origins of autobiographic memory. Psychological Science 4, 1-8.

Ollendick TH (1979). Fear reduction techniques with children. In Progress in Behavior Modification (ed. M. Hersen, R. M. Eisler and P. M. Miller), pp. 127-168. Academic Press: New York.

Ollendick TH, King NJ (1991). Origins of childhood fears : an evaluation of Rachman's theory of fear acquisition. Behavior Research and Therapy 29, 117-123.

Parker G (1983). Parental Overprotection: A Risk Factor in Psychosocial Development. Grune and Stratton: New York.

Phillips NK, Hammen CL, Brennan PA, Najman JM, Bor W (2005). Early adversity and the prospective prediction of depressive and anxiety disorders in adolescents. Journal of Abnormal Child Psychology 33, 13-24.

Rachman S (1990). The determinants and treatment of simple phobias. Advances in Behavior Research and Therapy 12, 1-30.

Rapee RM (2001). The development of generalized anxiety disorder. In The Developmental Psychopathology of Anxiety (ed. M. W. Vasey and M. R. Dadds), pp. 481-504. Oxford University Press: New York. 
Rapee RM, Spence SH (2004). The etiology of social phobia: empirical evidence and an initial model. Clinical Psychology Review 24, 737-767.

Rickman M, Davidson R (1994). Personality and behavior in parents of temperamentally inhibited or uninhibited children. Developmental Psychology 30, 346-354.

Rosenbaum JF, Biederman J, Gersten M, Hirshfeld DR, Meminger SR, Herman JB, Kagan J, Reznick JS, Snidman N (1988). Behavioral inhibition in parents of children with panic disorder and agoraphobia: a controlled study. Archives of General Psychiatry 45, 463-470.

Rosenbaum JF, Biederman J, Hirshfield DR, Bolduc EA, Faraone SV, Kagan J, Snidman N, Reznick JS (1991). Further evidence of an association between behavioral inhibition and anxiety disorders: results from a family study of children from a non-clinical sample. Journal of Psychiatric Research 25, 49-65.

Rosenbaum JF, Biederman J, Hirshfeld-Becker DR, Kagan J, Snidman N, Friedman D, Nineberg A, Gallery DJ, Faraone SV (2000). A controlled study of behavioral inhibition in children of parents with panic disorder and depression. American Journal of Psychiatry 157, 2002-2010.

Rubin KH, Burgess KB, Hastings PD (2002). Stability and social-behavioral consequences of toddlers' inhibited temperament and parenting behaviors. Child Development 73, 483-495.

Schmidt LA, Fox NA, Rubin KH, Hu S, Hamer DH (2002). Molecular genetics of shyness and aggression in preschoolers. Personality and Individual Differences 33, 227-238

Schwartz C, Snidman N, Kagan J (1999). Adolescent social anxiety as an outcome of inhibited temperament in childhood. Journal of the American Academy of Child and Adolescent Psychiatry 38, 1008-1015.

Shanahan L, Copeland W, Costello EJ, Angold A (2008). Specificity of putative psychosocial risk factors for psychiatric disorders in children and adolescents. Journal of Child Psychology and Psychiatry 49, 34-42.

Silove D, Manicavasagar V, O'Connell D, Morris-Yates A (1995). Genetic factors in early separation anxiety: implications for the genesis of adult anxiety disorder. Acta Psychiatrica Scandanavica 92, 17-24.

Stubbe DE, Zahner GE, Goldstein MJ, Leckman JF (1993). Diagnostic specificity of a brief measure of expressed emotion: a community study of children. Journal of
Child Psychology and Psychiatry and Allied Disciplines 34, 139-154.

Suveg C, Zeman J, Flannery-Schroeder E, Cassano M (2005).

Emotion socialization in families of children with an anxiety disorder. Journal of Abnormal Child Psychology 33, 145-155.

Swearingen EMC, Cohen LH (1985). Life events and psychological distress: a prospective study of young adolescents. Developmental Psychology 21, 1045-1054.

Thapar A, McGuffin P (1995). Are anxiety symptoms in childhood heritable? Journal of Child Psychology and Psychiatry 36, 439-447.

Turner SM, Biedel DC, Costello A (1987). Psychopathology in the offspring of anxiety disordered patients. Journal of Consulting and Clinical Psychology 55, 229-235.

Turner SM, Beidel DC, Wolff PL (1996). Is behavioral inhibition related to the anxiety disorders? Clinical Psychology Review 16, 157-172.

Warner V, Mufson L, Weissman MM (1995). Offspring at low and high risk for depression and anxiety: mechanisms of psychiatric disorder. Journal of the Academy of Child and Adolescent Psychiatry 34, 786-797.

Warren SL, Emde RN, Sroufe LA (2000). Internal representations: predicting anxiety from children's play narratives. Journal of the American Academy of Child and Adolescent Psychiatry 39, 100-107.

Warren SL, Simmens SJ (2005). Predicting toddler anxiety/ depressive symptoms: effects of caregiver sensitivity on temperamentally vulnerable children. Infant Mental Health Journal 26, 40-55.

Weissman MM, Leckman JF, Merikangas KR, Gammon GD, Prusoff BA (1984). Depression and anxiety disorders in parents and children. Archives of General Psychiatry 41, 845-852.

Whaley SE, Pinto A, Sigman M (1999). Characterizing interactions between anxious mothers and their children. Journal of Consulting and Clinical Psychology 67, 826-836.

Wood JJ, McLeod BD, Sigman M, Hwang W, Chu BC (2003). Parenting and childhood anxiety: theory, empirical findings, and future directions. Journal of Child Psychology and Psychiatry 44, 134-151.

Wood JJ, Piacentini JC, Southam-Gerow M, Chu BC, Sigman M (2006). Family cognitive behavioral therapy for child anxiety disorders. Journal of the American Academy of Child and Adolescent Psychiatry 45, 314-321. 